\title{
Assessing the deposition and canopy penetration of nozzles with different spray qualities in an oat (Avena sativa L.) canopy
}

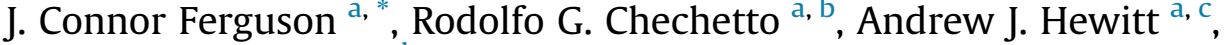 \\ Bhagirath S. Chauhan ${ }^{\mathrm{d}}$, Steve W. Adkins ${ }^{\mathrm{a}}$, Greg R. Kruger ${ }^{\mathrm{c}}$, Chris C. O'Donnell ${ }^{\text {a }}$ \\ a The University of Queensland, Gatton 4343, Queensland, Australia \\ b São Paulo State University - FCA, Department of Rural Engineering, Botucatu, São Paulo, Brazil \\ ${ }^{\mathrm{c}}$ University of Nebraska-Lincoln, North Platte 69101, NE, USA \\ ' Queensland Alliance for Agriculture and Food Innovation (QAAFI), The University of Queensland, Toowoomba 4350, Queensland, Australia
}

\section{A R T I C L E I N F O}

\section{Article history:}

Received 4 September 2015

Received in revised form

24 November 2015

Accepted 26 November 2015

Available online 17 December 2015

\section{Keywords:}

Spray quality

Application volume rate

Coverage

Droplet number density

Nozzle

Spray drift

Pesticide efficacy

\begin{abstract}
A B S T R A C T
Consistent spray coverage that is evenly distributed throughout the canopy is necessary to control pest populations that can negatively affect yield. As applicators are switching to Coarser spray quality nozzles to reduce risk and liability of pesticide spray drift, concerns about efficacy loss are growing. Previous research has indicated that small droplets are the most effective at penetrating through crop canopies, but newer nozzle technologies have improved the effectiveness of larger droplet or Coarser sprays. Research was conducted to assess the canopy penetration of nozzles that produce Coarse, Very-Coarse and Extremely-Coarse spray qualities compared to nozzles that produce Fine and Medium spray qualities. Kromekote collectors were positioned in four configurations in an oat (Avena sativa L.) var. 'Yarran' (AusWest Seeds, Forbes, NSW, Australia) crop to quantify the coverage and droplet number densities (droplets $\mathrm{cm}^{-2}$ ) across three application carrier volume rates: 50, 75 and $100 \mathrm{~L} \mathrm{ha}^{-1}$. Applications were made in the field in $30 \mathrm{~cm}$ tall, tillering oats, with collectors arranged in a randomised complete block design with three replications. The entire study was repeated on the following day. Results showed that droplet number densities were inversely related to the droplet size produced by the nozzles, yet coverage was increased more by application volume rate than droplet size. Thus, both spray drift reduction and improved canopy penetration can be achieved with proper nozzle selection and operation parameters for the control of agronomic pests.
\end{abstract}

() 2015 Elsevier Ltd. All rights reserved.

\section{Introduction}

Crop canopy penetration is important for pesticide efficacy, especially for the control of invertebrate and fungal pests. Poorly distributed sprays in a crop canopy reduce the effectiveness of a spray application (Uk and Courshee, 1982; Wolf et al., 2000), which can cause growers and applicators to have to reapply their sprays to achieve adequate pest control. Post-emergence herbicide efficacy is directly related to the ability to penetrate through crop canopies (Knoche, 1994). Concerns about spray drift have led to the adoption of Venturi and other nozzle types which seek to increase droplet size to reduce this risk (Ferguson et al., 2015). The spray droplet size is the greatest factor affecting spray drift in broadacre crops (Hewitt, 1997) and droplets with diameters smaller than $100 \mu \mathrm{m}$

\footnotetext{
* Corresponding author.

E-mail address: j.ferguson@uq.edu.au (J.C. Ferguson).
}

have the greatest tendency to drift (Grover et al., 1978; Byass and Lake, 1977). When the droplet diameter is below $200 \mu \mathrm{m}$, deposition is influenced primarily by atmospheric and wake effects from the sprayer (Spillman, 1984) which often cause droplets to be captured in the upper portion of a plant canopy (Uk and Courshee, 1982). Physics dictates that a projected object with more mass under the influence of gravity would experience greater momentum which should cause it to move deeper into dense canopies (Spillman, 1984).

Droplet size classification is based on a standard developed by the British Crop Protection Council (Southcombe et al., 1997) that has been updated and approved under the American Society of Agricultural and Biological Engineers (ASABE, formerly ASAE) producing the current version of its S572.1 standard in 2009 (ASAE, 2009). The droplet size classes according to the ASAE standard (in increasing droplet size order) are: Extremely-Fine, Very-Fine, Fine, Medium, Coarse, Very-Coarse, Extremely-Coarse, and Ultra-Coarse. 
The exact delineation of the size classes are based on a set of certified reference nozzles and each laboratory's droplet measurement system (ASAE, 2009).

Previous studies have examined droplet coverage and canopy penetration across a range of nozzle types (Knoche, 1994; Zhu et al., 2004; Derksen et al., 2008; Hanna et al., 2009; Wolf and Daggupati, 2009) and found varying results. The results generally fall into two categories: smaller droplets penetrate canopies better (Knoche, 1994; Wolf and Daggupati, 2009), or smaller droplets do not penetrate canopies better than large droplets (Zhu et al., 2004; Derksen et al., 2008; Hanna et al., 2009). Many of the studies appraised in the Knoche (1994) review occurred well before Venturi nozzle technology was developed. Wolf and Daggupati (2009) observed improved canopy penetration below a dense soybean (Glycine max (L.) Merr.) crop from Fine and Medium spray quality nozzles. Nozzles in that study were classified as Fine, Medium or Coarse. Hanna et al. (2009) compared Fine, Medium, and Coarse spray quality nozzles at three heights in a soybean canopy, but unlike Wolf and Daggupati (2009), observed no difference in droplet size and canopy penetration or coverage. Venturi nozzles led to higher deposits in a peanut (Arachis hypogaea L.) canopy as compared to non-Venturi nozzles across three collector heights, and especially at the bottom collector (Zhu et al., 2004). This result was also observed by Derksen et al. (2008) where Fine spray quality nozzles reduced deposits compared to Coarser spray quality nozzles in a soybean crop.

Application carrier volume rate has an effect on the performance of certain pesticides. In some cases, a lower volume rate can increase both coverage and efficacy (Fritz et al., 2005, 2007). Smaller droplets tend to have a greater affinity for plant surfaces, especially on grasses due to their primarily vertical orientation (Lake, 1977; Spillman, 1984), but this does not seem to impact herbicide efficacy. In 56\% of studies examined by Knoche (1994), a decrease in the application volume rate led to an improvement or no effect on the efficacy of herbicides. This is consistent with other studies (McMullan, 1995; Etheridge et al., 2001; Ramsdale and Messersmith, 2001), conducted after 1994. Changing the spray droplet size will impact the deposition, but the effect on coverage was not as correlated (Hanna et al., 2009); Wolf and Daggupati, 2009).

Relatively few studies have explored the effect of nozzle type and droplet size on spray deposition rates and cereal canopy penetration for a fixed liquid flow and spray pressure. The objectives of this study are: 1 ) assess the coverage and droplet number densities (droplets $\mathrm{cm}^{-2}$ ) from five different spray quality nozzles with four collector arrangements in an oat canopy. 2) Quantify the crop canopy penetration with different droplet size classes to determine if a greater percentage of small droplets in a spray will improve crop canopy penetration. 3) Understand the relationship between spray volume rate and crop canopy penetration.

\section{Materials and methods}

\subsection{Nozzles and application parameters}

A study to examine canopy penetration and coverage across nozzle type and application volume rate was conducted at the University of Queensland, Gatton, Queensland, Australia. Nozzle types that span across five spray qualities at a standard pressure and flow rate were selected to compare deposition and canopy penetration in an oat canopy. The study compared nine nozzle types listed in Table 1 across five different ASABE S572.1 spray quality categories as tested in Table 2. The XR 11003VS operated at $300 \mathrm{kPa}$ was included for comparison as it is the reference nozzle used in international drift reduction technology (DRT) studies (van de Zande et al., 2002; ISO, 2006, 2008, 2010). Each nozzle except the XR 11003VS (which was operated at $300 \mathrm{kPa}$ ), was operated at $350 \mathrm{kPa}$. This pressure was selected based on work from a previous study (Ferguson et al., 2015) where this pressure was a standard pressure within the standard operating parameters for each nozzle type. Treatments were made using a $6 \mathrm{~m}$ pull-behind quad bike sprayer. Application volume rates in the study were 50,75 , and $100 \mathrm{~L} \mathrm{ha}^{-1}$ applied at driving speeds listed in Table 1 . Nozzle spacing was $50 \mathrm{~cm}$ and boom height was $85 \mathrm{~cm}$ above the ground, $50 \mathrm{~cm}$ above the top collectors.

\subsection{Collector description and placement}

Collectors were $3 \times 5 \mathrm{~cm}$ Kromekote cards sprayed with water $+1 \mathrm{~g} \mathrm{~L}^{-1}$ addition of Brilliant Blue (Tintex Dyes, Kelvin Grove, QLD Australia), placed at one of four positions: ground, lower canopy, middle canopy, and top canopy. The use of Kromekote cards for deposition analysis have been described before (Johnstone, 1960; Higgins, 1967; Hewitt and Meganasa, 1993). Each collector type was positioned on a $5 \times 8 \mathrm{~cm}$ flat metal plate attached to a post that was driven in the ground at various depths (Fig. 1). The ground cards were placed $10 \mathrm{~cm}$ above the ground and left in open space. The lower canopy cards were placed on metal plates at $17 \mathrm{~cm}$ above the ground with four $30 \mathrm{~cm}$ tall oat plants in $10 \mathrm{~cm}$ pots placed in a square around the collector. The middle canopy collectors were positioned at $20 \mathrm{~cm}$ above the ground, and $10 \mathrm{~cm}$ above the soil surface of oat plants which were situated as described with the lower canopy. The top collectors were placed at $35 \mathrm{~cm}$ above the ground and just above the tips of the oat plants, positioned as mentioned above (Fig. 1). Each collector type was positioned in a randomized complete block design with three replications. There were 576 cards in total with 72 for each nozzle type, and six for each nozzle type by spray volume rate by collector position. The study was applied on June 9th and then the entire study repeated on June 10th, 2015.

\subsection{Oat planting and growing conditions}

Oats were planted individually (one seed per pot) at a $6 \mathrm{~cm}$ depth. Seeds were planted into plastic pots $(10 \times 10 \mathrm{~cm}$ diameter), filled with $0.5 \mathrm{~L}$ of a standard University of Queensland Gatton nursery potting media ( $1 \mathrm{~m}^{3}$ of composted pine bark $(2-10 \mathrm{~mm})$; $2 \mathrm{~kg}$ Osmocote Plus 8-9 month (NPK: $15.0+3.9+9.1 \mathrm{~g}$ plus $1.5 \mathrm{~g} \mathrm{Mg}$ and trace elements); $1 \mathrm{~kg}$ Osmocote Exact $+3-4$ month (NPK: $16.0+5+9.2 \mathrm{~g}$ plus $1.8 \mathrm{~g} \mathrm{Mg}$ and trace elements); $2 \mathrm{~kg}$ Nutricote 7 month (NPK: $16.0+4.4+8.3$ g plus trace elements); $1.2 \mathrm{~kg}$ Saturaid granular wetting agent; $1.2 \mathrm{~kg}$ Dolomite; $1.3 \mathrm{~kg}$ Osmoform 4 month release (IBDU) (NPK: $18.0+2.2+11.0$ g plus trace elements). Plants were grown outside and irrigated twice daily. Pots were placed into $0.5 \times 0.4 \mathrm{~m}$ trays ( 20 pots per tray) and trays were rearranged every 4 days in a completely randomised design to ensure conditions would be evenly spread out across pots. At the time of the study, oat plants were at the tillering stage, measuring $25-32 \mathrm{~cm}$ in height. Plants were placed around the collector positions as described above and plants were removed after the first day of spraying and new plants were placed out the second day.

\subsection{Card analysis}

Each card was separately photographed on a light table using a high resolution digital-single-lens-reflex (DSLR) camera positioned at a $10 \mathrm{~cm}$ height above the light table. Photographs of the sprayed cards were analysed using Image J software (Rasband, 2008). Each card was cropped to remove background area, changed into 8-bit 
Table 1

Nozzles listed with their respective operating parameters and the driving speeds for each of the three application volume rates used in the study.

\begin{tabular}{|c|c|c|c|c|c|c|}
\hline \multirow[t]{2}{*}{ Nozzle type } & \multirow[t]{2}{*}{ Angle and flow rate } & \multirow[t]{2}{*}{ Manufacturer } & \multirow[t]{2}{*}{ Operating pressure } & \multicolumn{3}{|c|}{ Driving speed } \\
\hline & & & & $50 \mathrm{~L} \mathrm{ha}^{-1}$ & $75 \mathrm{~L} \mathrm{ha}^{-1}$ & $100 \mathrm{~L} \mathrm{ha}^{-1}$ \\
\hline & & & $\mathrm{kPa}$ & & $\mathrm{km} \mathrm{h}^{-1}$ & \\
\hline XR (reference) & 11003 & Spraying Systems Inc. & 300 & 28.8 & 19.2 & 14.4 \\
\hline $\mathrm{XR}$ & 11002 & Spraying Systems Inc. & 350 & 20.7 & 13.8 & 10.4 \\
\hline TT & 11002 & Spraying Systems Inc. & 350 & 20.7 & 13.8 & 10.4 \\
\hline TDADF & 11002 & Agrotop GmbH & 350 & 20.7 & 13.8 & 10.4 \\
\hline AIXR & 11002 & Spraying Systems Inc. & 350 & 20.7 & 13.8 & 10.4 \\
\hline MD & 11002 & Hardi International & 350 & 20.7 & 13.8 & 10.4 \\
\hline AI & 11002 & Spraying Systems Inc. & 350 & 20.7 & 13.8 & 10.4 \\
\hline TTI & 11002 & Spraying Systems Inc. & 350 & 20.7 & 13.8 & 10.4 \\
\hline
\end{tabular}

Table 2

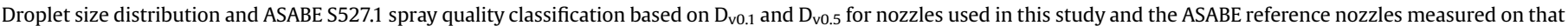
day.

\begin{tabular}{|c|c|c|c|c|c|}
\hline Nozzle & $\begin{array}{l}\text { Pressure } \\
\mathrm{kPa}\end{array}$ & $\begin{array}{l}\mathrm{D}_{\mathrm{v} 0.1} \\
\mu \mathrm{m}\end{array}$ & $\begin{array}{l}D_{\mathrm{v} 0.5} \\
\%\end{array}$ & $<150 \mu \mathrm{m}$ & ASABE classification \\
\hline 11001 & 450 & 57 & 112 & 73.5 & Very-Fine/Fine \\
\hline XR 11002 & 350 & 76 & 157 & 43.3 & Fine \\
\hline XR 11003 & 300 & 90 & 213 & 25.5 & Fine \\
\hline 11003 & 300 & 95 & 220 & 26.2 & Fine/Medium \\
\hline TurboTeejet 11002 & 350 & 120 & 279 & 15.9 & Medium \\
\hline TDADF 11002 & 350 & 176 & 365 & 6.6 & Medium \\
\hline Mini Drift $11002^{*}$ & 350 & 167 & 375 & 7.6 & Medium \\
\hline 11006 & 200 & 180 & 373 & 6.0 & Medium/Coarse \\
\hline Mini Drift $11002^{*}$ & 350 & 167 & 375 & 7.6 & Coarse \\
\hline AIXR 11002 & 350 & 188 & 381 & 6.2 & Coarse \\
\hline 8008 & 250 & 222 & 456 & 3.5 & Coarse/Very-Coarse \\
\hline AI 11002 & 350 & 261 & 499 & 2.0 & Very-Coarse \\
\hline 6510 & 200 & 288 & 585 & 1.6 & Very-Coarse/Extremely-Coarse \\
\hline TTI 11002 & 350 & 360 & 722 & 0.6 & Extremely-Coarse \\
\hline 6515 & 150 & 382 & 729 & 0.5 & Extremely-Coarse/Ultra-Coarse \\
\hline
\end{tabular}

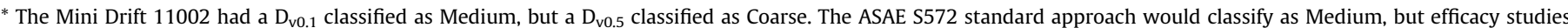
generally use the $D_{\mathrm{v} 0.5}$ for droplet size classification. Thus it has been included twice and classified differently based on the $D_{\mathrm{v} 0.1}$ or $\mathrm{D}_{\mathrm{v} 0.5}$.
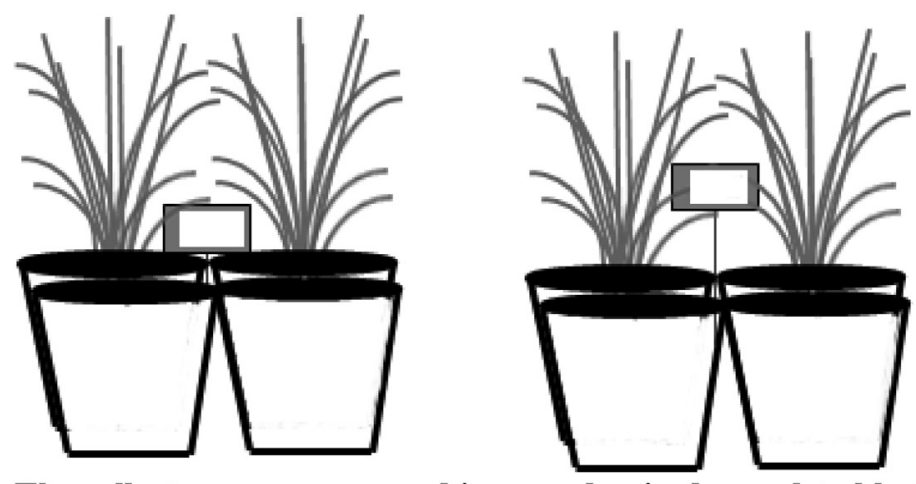

The collectors were arranged in a randomised complete block design with 3 replications.
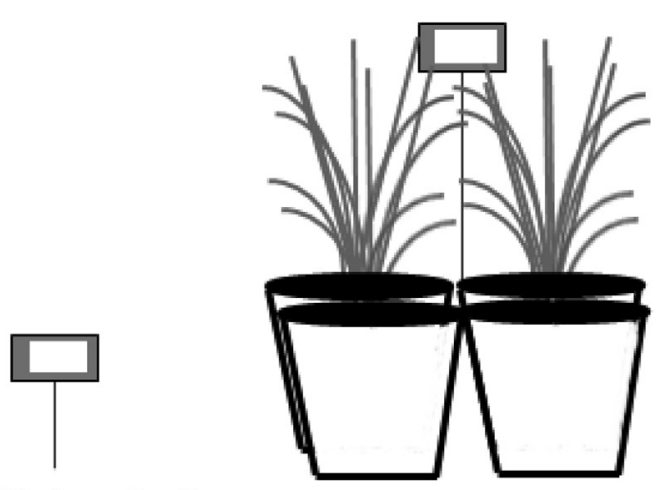

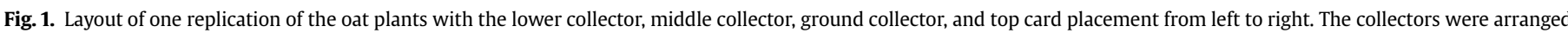
in a randomised complete block design with 3 replications.

format, and then individually threshold adjusted to ensure that only sprayed droplets were included in the sample analysis. Each image was analysed for droplet number density and percent coverage. Coverage was determined as the percent cover of the card from the blue dye of deposited droplets.

\subsection{Droplet size analysis}

The sprays were analysed for droplet size distribution spectra in the Centre for Pesticide Application and Safety (CPAS) Wind Tunnel Research Facility at the University of Queensland on June 19, 2015.
Wind speed was set at $8.0 \mathrm{~m} \mathrm{~s}^{-1}$, a required speed to avoid a spatial sampling bias (SDTF, 1997). Each treatment was analysed on a laser diffraction instrument (Sympatec Helos Sympatec Inc., Clausthal, Germany) to measure droplet size from each nozzle type. The laser diffraction instrument was placed $30 \mathrm{~cm}$ downwind from the nozzle, to allow for full liquid sheet breakup. Nozzles were actuated in a downward direction to allow the spray plume to pass through the measurement area for $9 \mathrm{~s}$ per measurement. The volumetric droplet size spectra parameters selected for data interpretation were the $D_{v 0.1}, D_{v 0.5}$, and the \% of the spray volume contained in droplets with a diameter $<150 \mu \mathrm{m}$ (used often to classify the 
'driftable fines' for a treatment). These parameters were selected because they are widely used to assess spray drift potential $\left(D_{\mathrm{v} 0.1}\right.$ and $\%<150 \mu \mathrm{m})\left(\right.$ SDTF, 1997) and efficacy potential $\left(D_{\mathrm{v} 0.5}\right)$. The $D_{v 0.1}$ is the diameter at which $10 \%$ of the volume of droplets are contained in droplets at or below that diameter. The $\mathrm{D}_{\mathrm{v} 0.5}$ (volume median diameter) is the diameter at which half of the volume is contained in droplets of larger or smaller diameter to help classify sprays for efficacy potential, and understand the size classification of each. In order to help classify the nozzle treatments, the ASABE references nozzles were also measured at the same time, a method consistent with ASABE S572.1 (ASAE, 2009).

\subsection{Statistical analyses}

Collector coverage and droplet number density were analysed in separate generalised linear mixed models (PROC GLIMMIX) in SAS (Statistical Analysis Software, version 9.4, Cary, North Carolina, USA) with means separations made at the $\alpha=0.05$ level. Both models were analysed separately for each of the four collector placements: coverage or droplet number density = nozzle type $\mathrm{x}$ volume rate $\mathrm{x}$ application day and block was randomised. Fixed effects were nozzle type, application volume rate, and application day. The denominator degrees of freedom (df) was protected from bias through the inclusion of the Kenward-Roger adjustment for the generalised linear mixed model (Kenward and Roger, 1997). The Sidak adjustment was included in comparisons of variables to improve the power and confidence in reported differences (Sidak, 1967). Application day was not significant, thus data were pooled, giving six replications of each nozzle $\mathrm{x}$ application volume rate $\mathrm{x}$ collector placement treatment.

A separate generalised linear mixed model was constructed for the droplet size data, where the Dv0.5 with water was analysed by nozzle type. The Kenward-Rogers and Sidak adjustments were both included as described above.

\section{Results}

\subsection{Application conditions over both study days}

Environmental conditions did not vary across both application days, except that the temperature was $3{ }^{\circ} \mathrm{C}$ cooler, and the relative humidity was $11 \%$ higher on the second day (Table 3 ). The data for both the coverage and the droplet number density were not significant across days, thus data points were pooled.

\subsection{Droplet size analysis}

Nozzles were classified based on results from the ASABE reference nozzles taken during the same wind tunnel period. When operated at $350 \mathrm{kPa}$, the TDADF 11002, AI 11002, and TTI 11002 were all classified as a droplet size category smaller than the classification listed in their respective nozzle catalogues (Table 2). The greatest difference in droplet size was across nozzles of different spray qualities. The AIXR 11002 and MD 11002 were not different at the $D_{v 0.5}$ (Table 4 ). The Fine and Medium spray quality nozzles were not similar, and each of the other spray qualities were different
(Table 4).

\subsection{Droplet number density}

Nozzle type was significant ( $p<0.001$ ) for droplet number density as was the nozzle type by spray volume rate $(p=0.001)$ (Table 5). The nozzles that produce a Fine spray quality XR 11002 nozzle had the highest droplet number density across collector positions (Table 5 ) followed by the larger $D_{v 0.5}$ Fine spray quality nozzle, XR 11003. The trend followed where the Medium spray quality nozzles (TT 11002, TDADF 11002) had the next highest droplet number density. This trend continued until the TTI 11002 , an Extremely-Coarse spray quality nozzle, which produced the lowest droplet number density across collector type (Table 4). There was not a correlation between droplet number density and coverage. The canopy appeared to have little effect on droplet number density across nozzle types. In the case of Coarse, VeryCoarse and Extremely-Coarse spray quality nozzles, (AIXR 11002, MD 11002, AI 11002 and the TTI 11002) the canopy increased the droplet number density. This trend was not the case with the XR 11002, XR 11003, and the TT 11002 (Table 4).

The significant interaction with nozzle by volume rate was dependent on nozzle type. The Fine spray quality nozzles (XR 11002 and XR 11003) resulted in a trend where increasing the application volume from 50 to $100 \mathrm{~L} \mathrm{ha}^{-1}$ reduced the droplet number density (115-90 and 99 to 82 respectively). The Medium spray quality nozzle (TT 11002), Medium/Coarse spray quality nozzle (MD 11002), and the Very-Coarse spray quality nozzle (AI 11002) did not see a change in their droplet number density. The trend of increased droplet number densities with increased volume rate was observed with the TDADF 11002, AIXR 11002, and TTI 11002.

\subsection{Coverage}

The relationship between coverage and application volume rate was significant $(\mathrm{p}<0.001)$ as was the relationship between coverage and nozzle type $(\mathrm{p}<0.001)$ for each collector position (Table 6). The $100 \mathrm{~L} \mathrm{ha}^{-1}$ volume rate resulted in the highest coverage across nozzle and collector type (39\%) and the $50 \mathrm{~L} \mathrm{ha}^{-1}$ volume resulted in the lowest coverage (21\%). The $75 \mathrm{~L} \mathrm{ha}^{-1}$ volume rate resulted in an overall coverage of $30 \%$, which fits the linear trend that with each increase of $25 \mathrm{~L} \mathrm{ha}^{-1}$ application volume rate, coverage is increased by $9 \%$ (Table 7 ). Coverage was similar at the top collector placement between the Fine (XR 11002, XR 11003) and Medium (TT 11002) spray quality nozzles (Table 2). Coverage was also similar across the rest of the nozzles classified as Medium or Coarser, including the Extremely-Coarse TTI 11002. The XR 11002 and the XR 11003 always had a similar coverage across each collector position (Table 2). This was also the case for the AI 11002 and the TTI 11002. At the middle canopy placement, the XR 11002 had a similar coverage to the Medium (TDADF 11002) and the Coarse spray quality nozzles (AIXR 11002 and MD 11002). At the lower canopy collector position, the XR 11003 was similar to the AIXR 11002 and TDADF 11002, but not the TT 11002 which resulted in a lower coverage (Table 4). At the ground collector position, the Fine XR 11002 was similar to the Coarse AIXR 11002.

Table 3

Weather data for the two days of the study on June 9 and 10, 2015. Weather data taken was summarised only for the hours of the day for which spraying occurred.

\begin{tabular}{|c|c|c|c|c|c|}
\hline \multirow[t]{2}{*}{ Date } & Avg. Temp & Avg. Dew point & Avg. RH & Wind speed and direction & Gust \\
\hline & $\left({ }^{\circ} \mathrm{C}\right)$ & $\left({ }^{\circ} \mathrm{C}\right)$ & $(\%)$ & $\left(\mathrm{km} \mathrm{hour}^{-1} / \mathrm{NNE}\right)$ & $\left(\mathrm{km} \mathrm{hour}^{-1}\right)$ \\
\hline $09 / 06 / 2015$ & 20.7 & 11.6 & 56.9 & 8.0 & 11.5 \\
\hline $10 / 06 / 2015$ & 17.7 & 11.4 & 67.8 & 8.1 & 12.3 \\
\hline
\end{tabular}


Table 4

Droplet deposition results for each nozzle type listed by the collector position and the statistical breakdown for each model.

\begin{tabular}{|c|c|c|c|c|c|c|c|c|c|c|}
\hline \multirow[t]{2}{*}{ Nozzle } & \multirow[b]{2}{*}{$\begin{array}{l}\text { Pressure } \\
(\mathrm{kPa})\end{array}$} & \multirow[b]{2}{*}{$\begin{array}{l}\mathrm{D}_{\mathrm{v} 0.5} \\
(\mu \mathrm{m})\end{array}$} & \multicolumn{2}{|l|}{ Ground } & \multicolumn{2}{|l|}{ Lower } & \multicolumn{2}{|l|}{ Middle } & \multicolumn{2}{|l|}{ Top } \\
\hline & & & $\begin{array}{l}\text { Density } \\
\left(\mathrm{cm}^{-2}\right)\end{array}$ & $\begin{array}{l}\text { Coverage } \\
(\%)\end{array}$ & $\begin{array}{l}\text { Density } \\
\left(\mathrm{cm}^{-2}\right)\end{array}$ & $\begin{array}{l}\text { Coverage } \\
(\%)\end{array}$ & $\begin{array}{l}\text { Density } \\
\left(\mathrm{cm}^{-2}\right)\end{array}$ & $\begin{array}{l}\text { Coverage } \\
(\%)\end{array}$ & $\begin{array}{l}\text { Density } \\
\left(\mathrm{cm}^{-2}\right)\end{array}$ & $\begin{array}{l}\text { Coverage } \\
(\%)\end{array}$ \\
\hline XR 11003 (reference) & 300 & $213 \mathrm{E}$ & $92 \mathrm{~A}$ & $35.1 \mathrm{ab}$ & $90 \mathrm{AB}$ & $34.4 \mathrm{ab}$ & $96 \mathrm{~A}$ & $36.4 \mathrm{ab}$ & $89 \mathrm{~A}$ & $37.7 \mathrm{ab}$ \\
\hline AI 11002 & 350 & $499 \mathrm{~B}$ & $37 \mathrm{CD}$ & $20.2 \mathrm{e}$ & $46 \mathrm{DC}$ & $24.5 \mathrm{~d}$ & $37 \mathrm{CD}$ & $22.9 \mathrm{~cd}$ & $34 \mathrm{BC}$ & $25.2 \mathrm{c}$ \\
\hline AIXR 11002 & 350 & $381 C$ & $57 \mathrm{~B}$ & 30.9 abc & $56 C$ & $31.7 \mathrm{bc}$ & $54 \mathrm{BC}$ & $30.7 \mathrm{ab}$ & $53 \mathrm{~B}$ & $34.2 \mathrm{abc}$ \\
\hline Mini Drift 11002 & 350 & $375 C$ & $46 \mathrm{BC}$ & $29.3 \mathrm{bc}$ & $52 \mathrm{C}$ & $28.4 \mathrm{~cd}$ & $57 \mathrm{BC}$ & $30.5 \mathrm{ab}$ & $56 \mathrm{~B}$ & $30.9 \mathrm{abc}$ \\
\hline TDADF 11002 & 350 & $365 C$ & $60 \mathrm{~B}$ & $28.5 \mathrm{c}$ & $57 C$ & 31.9 bc & $62 \mathrm{~B}$ & $34.2 \mathrm{ab}$ & $57 \mathrm{~B}$ & $32.1 \mathrm{abc}$ \\
\hline TurboTeejet 11002 & 350 & $279 \mathrm{D}$ & $82 \mathrm{~A}$ & $26.8 \mathrm{~cd}$ & $79 \mathrm{~B}$ & $26.9 \mathrm{~cd}$ & $100 \mathrm{~A}$ & $29.0 \mathrm{bc}$ & $88 \mathrm{~A}$ & $30.1 \mathrm{abc}$ \\
\hline TTI 11002 & 350 & $722 \mathrm{~A}$ & $26 \mathrm{D}$ & 21.0 de & $30 \mathrm{D}$ & $23.5 \mathrm{~d}$ & $29 \mathrm{D}$ & $21.5 \mathrm{~d}$ & $27 C$ & $26.0 \mathrm{bc}$ \\
\hline XR 11002 & 350 & $157 \mathrm{~F}$ & $95 \mathrm{~A}$ & $36.6 \mathrm{a}$ & $104 \mathrm{~A}$ & $37.4 \mathrm{a}$ & $100 \mathrm{~A}$ & $37.5 \mathrm{a}$ & $105 \mathrm{~A}$ & $38.3 \mathrm{a}$ \\
\hline
\end{tabular}

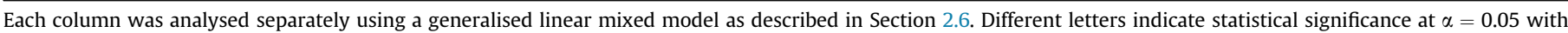

Sidak's adjustment. Each column was analysed separately, denoted with the uppercase and lowercase letters to indicate differences.

Table 5

Droplet number density Type III Test across nozzle type, spray volume rate and collector position with the Kenward-Roger adjustment.

\begin{tabular}{lclrr}
\hline Type III test of fixed effects & Num df & Den df & F Value & $\mathrm{Pr}>$ F \\
\hline Effect & 7 & 475 & 119.69 & $<0.001$ \\
\hline nozzle & 3 & 475 & 1.54 & 0.204 \\
collector-position & 21 & 475 & 0.91 & 0.574 \\
nozzle*collector-position & 2 & 475 & 0.07 & 0.931 \\
volume rate & 14 & 475 & 3.06 & 0.001 \\
nozzle* volume rate & 6 & 475 & 1.48 & 0.183 \\
collector-position* volume rate & 42 & 475 & 0.52 & 0.995 \\
nozzle* collector-position* volume rate & 42 & & &
\end{tabular}

Table 6

Coverage Type III Test across nozzle type, spray volume rate and collector placement with the Kenward-Roger adjustment.

\begin{tabular}{lclrr}
\hline Type III test of fixed effects & Num df & Den df & F Value & Pr > F \\
\hline Effect & 7 & 476 & 33.83 & $<0.001$ \\
\hline nozzle & 3 & 476 & 4.42 & 0.005 \\
collector-position & 21 & 476 & 0.52 & 0.961 \\
nozzle*collector-position & 2 & 476 & 262.51 & $<0.001$ \\
volume rate & 14 & 476 & 0.53 & 0.915 \\
nozzle* volume rate & 6 & 476 & 0.34 & 0.918 \\
collector-position* volume rate & 42 & 475 & 0.34 & 1.000 \\
nozzle* collector-position* volume rate & \multicolumn{3}{l}{} \\
\hline
\end{tabular}

Table 7

Coverage by volume rate comparisons pooled across nozzle type and collector placement with Sidak's adjustment.

\begin{tabular}{|c|c|c|c|}
\hline \multirow[t]{2}{*}{ Volume rate } & \multirow{2}{*}{$\begin{array}{l}\text { Estimate } \\
\%\end{array}$} & \multirow{2}{*}{$\frac{\text { vs. } 100 \mathrm{~L} \mathrm{ha}^{-1}}{\text { ADJ P Value }}$} & \multirow{2}{*}{$\frac{\text { vs. } 75 \mathrm{~L} \mathrm{ha}^{-1}}{\text { ADJ P Value }}$} \\
\hline & & & \\
\hline 100 & 39 & - & - \\
\hline 75 & 30 & $<0.001$ & - \\
\hline 50 & 21 & $<0.001$ & $<0.001$ \\
\hline
\end{tabular}

\subsection{Canopy penetration}

Canopy penetration was similar across all nozzle types. There was no observed difference in coverage across nozzle type when volume rate was consistent. Differences were observed in coverage from the top card compared against the ground card $(\mathrm{p}=0.002)$ but no differences observed in the droplet number density (Table 4). The middle and lower canopy cards had the greatest droplet number density, followed by the top card and ground cards respectively. The ground collector resulted in the lowest coverage for five of the eight total nozzles - without any plant material near the card.

\section{Discussion}

The droplet number densities were strongly correlated to the droplet size categories of the nozzles used in the study, where the smaller the $D_{\mathrm{v} 0.5}$, the greater the droplet number density (Tables 2 and 4). The interaction of volume rate on the droplet number density was nozzle dependent, but this was not the case with the interaction of volume rate on coverage which was consistent across nozzle type (Table 7). This result agrees with those of both Wolf and Daggupati (2009) and Hanna et al. (2009) (Table 5). Coverage was not as strongly correlated to droplet size, though the nozzles that resulted in the highest and lowest coverage across collector placement were the Finest and Coarsest spray quality nozzles respectively (Table 4). This result is consistent with Wolf and Daggupati (2009) and Hanna et al. (2009) where they also observed no clear trend with spray quality and coverage even though there was a clear link to droplet size and its effect on the droplet number density.

Coverage also varied with nozzle type. Across two collector positions, the AIXR 11002 had a higher coverage than the TDADF 11002 (Table 4). This was even more apparent where the AIXR 11002 had a higher coverage across each collector position than the TT 11002.

The coverage and the droplet number density did not appear to be affected by the presence of the canopy, and in some cases, the canopy increased both results. This suggests that the nozzle types were able to effectively penetrate the canopy to an equal degree, or that the canopy was not dense enough to have an effect. Studies by Wolf and Daggupati (2009), Hanna et al. (2009), Zhu et al. (2004), and Derksen et al. (2008) examined canopy penetration in a dense soybean or peanut canopy, and did observe some nozzle effect on canopy penetration. Wolf and Daggupati (2009) observed improved canopy penetration with Finer spray quality nozzles where the others observed equal to or better canopy penetration with Coarser spray quality nozzles (Zhu et al., 2004; Derksen et al., 2008; Hanna et al., 2009). The oat canopy is structurally different from both a peanut and soybean canopy and thus it may be hard to successfully compare results from the two. The Wolf and Daggupati (2009) study used only collectors at one location (the bottom of the canopy) so it is hard to know the total canopy effect from this study which would have been observable if multiple collector positions within the canopy were included. Results from the present study suggest that Coarser spray qualities are aided by the presence of the canopy as the Coarse, Very-Coarse, and Extremely-Coarse spray quality nozzles saw an increase in coverage and the droplet number density.

The spray volume rate effects on coverage across nozzle type 
and collector placement were clear (Table 6), but the effect was evenly distributed throughout the canopy. The higher volume rate led to a greater droplet deposition across the entirety of the study.

The results obtained from this study (Table 4) show the importance of making the proper nozzle selection, which can allow the applicator to select a Coarser spray quality nozzle such as the AIXR 11002 and improve their coverage compared to a smaller droplet producing nozzle such as the TT 11002. This was also observed with the Coarser spray quality nozzle such as the TTI which had a similar coverage across collector placement to the AI. This result can both effectively reduce the risk of spray drift as the AIXR had a $2.5 \mathrm{x}$ decrease in droplets less than $150 \mu \mathrm{m}$ compared to the TT and the TTI had a 4x decrease in droplets less than $150 \mu \mathrm{m}$ compared to the AI. With a growing concern of spray drift, results from this study can help to allay concerns of reduced coverage and subsequently reduced efficacy that follow discussions of adopting Coarser spray quality nozzles. There was also no loss in coverage due to the canopy for both the Very-Coarse AI 11002 and the Extremely-Coarse TTI 11002, which means that both could be adopted without perceived loss in efficacy.

The extrapolation of the results from this study and the effect on herbicide efficacy are difficult, but results from previous studies (Knoche, 1994; McMullan, 1995; Etheridge et al., 2001; Ramsdale and Messersmith, 2001) suggest that reduced coverage from reduced application volume rate did not affect efficacy with some pesticides. It is clear that coverage is reduced when spray volume rate is decreased (Table 7). These results would suggest then, that a minimum coverage is necessary to achieve acceptable levels of weed control. This level of coverage can be achieved with Coarser spray quality nozzles as long as the spray volume rate is sufficient. The trend with coverage in this study suggests that between $50 \mathrm{~L} \mathrm{ha}^{-1}$ and $100 \mathrm{~L} \mathrm{ha}^{-1}$ there is an $18 \%$ gain in coverage with an increase of $50 \mathrm{~L} \mathrm{ha}^{-1}$ spray volume rate (Table 7 ). This trend is unlikely to continue indefinitely but was consistent across nozzle type between these volume rates.

In summary, droplet size is an important factor influencing spray deposition and canopy penetration in most applications. It was observed that with the optimal nozzle choice, a Coarser spray quality nozzle can be selected to minimise spray drift potential and maximise coverage. Application volume rate affected coverage across collector placement, but there was less correlation with the volume rate effects on droplet number density which was nozzle dependent. Canopy effects aided in the deposition of Coarser spray quality nozzles, but did not reduce the coverage or droplet number density across nozzle type. Future efficacy studies will be conducted to apply results from this study to understand how volume rate and coverage affect control of weeds and if a minimum level of biologically effective coverage can be determined to further aid in nozzle and technology selection to reduce spray drift while achieving acceptable levels of control.

\section{Acknowledgements}

The authors acknowledge the Grains Research and Development Corporation of Australia (GRDC) for their support of this work through the project titled "Options for improved insecticide and fungicide use and canopy penetration in cereals and canola", UWA00165. The authors also would like to thank Peter Tame of AusWest Seeds for his support of this work by providing seed for this study.
American Society of Agricultural and Biological Engineers, St. Joseph, MI. Byass, J.B., Lake, J.R., 1977. Spray drift from a tractor-powered field sprayer. Pest. Sci. 8, 117-126.

Derksen, R.C., Zhu, H., Ozkan, H.E., Hammond, R.B., Dorrance, A.E., Spongberg, A.L., 2008. Determining the influence of spray quality, nozzle type, spray volume, and air-assisted application strategies on deposition of pesticides in soybean canopy. Trans. ASAE 51, 1529-1537.

Etheridge, R.E., Hart, W.E., Hayes, R.M., Mueller, I.C., 2001. Effect of venturi type nozzles and application volume on post-emergence herbicide efficacy. Weed Technol. 15, 75-80.

Ferguson, J.C., O'Donnell, C.C., Chauhan, B.S., Adkins, S.W., Kruger, G.R., Wang, R., Urach Ferreira, P.H., Hewitt, A.J., 2015. Determining the uniformity and consistency of droplet size across spray drift reducing nozzles in a wind tunnel. Crop Prot. 76, 1-6.

Fritz, B.K., Kirk, I.W., Hoffmann, W.C., Martin, D.E., Hofman, V.I., Hollingsworth, C., McMullen, M., Halley, S., 2005. Aerial application methods for increasing spray deposition on wheat heads. Appl. Eng. Agric. 22, 357-364.

Fritz, B.K., Hoffmann, W.C., Martin, D.E., Thomson, S.J., 2007. Aerial application methods for increasing spray deposition on wheat heads. Appl. Eng. Agric. 23, 709-715.

Grover, R., Kerr, L.A., Maybank, J., Yoshida, K., 1978. Field measurements of droplet drift from ground sprayers. Can. J. Plant Sci. 58, 611-622.

Hanna, H.M., Robertson, A.E., Carlton, W.M., Wolf, R.E., 2009. Nozzle and carrier application effects on control of soybean leaf spot diseases. Appl. Eng. Agric. 25, $5-13$.

Hewitt, A.J., 1997. The Importance of droplet size in agricultural spraying. Atomization Sprays 7, 235-244.

Hewitt, A.J., Meganasa, T., 1993. Droplet distribution densities of a pyrethroid insecticide within grass and maize canopies for the control of Spodoptera exempta larvae. Crop Prot. 12, 59-62.

Higgins, A.H., 1967. Spread factors for technical malthion. J. Econ. Ent 62, 912-916.

ISO 22369-2, 2010. Crop Protection Equipment - Drift Classification of Spraying Equipment - Part 2: Classification of Field Crop Sprayers by Field Measurements. International Organization for Standardization, Geneva.

ISO 22856, 2008. Equipment for Crop Protection - Methods for the Laboratory Measurement of Spray Drift - Wind Tunnels. International Organization for Standardization, Geneva.

ISO 22369-1, 2006. Crop Protection Equipment - Drift Classification of Spraying Equipment Part 1: Classes. International Organization for Standardization, Geneva.

Johnstone, D.R., 1960. Assessment Techniques 2. Photographic Paper, p. 13. CPRU Porton Report No. 177. Mimeographed.

Kenward, M.G., Roger, J.H., 1997. Small sample interference for fixed effects from restricted maximum likelihood. Biometrics 53, 983-997.

Knoche, M., 1994. Effect of droplet size and carrier volume on performance of foliage-applied herbicides. Crop Prot. 13, 163-178.

Lake, J.R., 1977. The effect of drop size and velocity on the performance of agricultural sprays. Pest. Sci. 8, 515-520.

McMullan, P.M., 1995. Effect of spray volume, spray pressure and adjuvant volume on efficacy of sethoxydim and fenoxaprop-p-ethyl. Crop Prot. 14, 549-554.

Ramsdale, B.K., Messersmith, C.G., 2001. Drift-reducing nozzle effects on herbicide performance. Weed Technol. 15, 453-460.

Rasband, W.S., 2008. ImageJ. U. S. National Institutes of Health, Bethesda, Maryland, USA, pp. 1997-2008.

SDTF, 1997. Spray Drift Task Force Study A95-010, Miscellaneous Study Nozzle Study. EPA MRID No. 44310401.

Sidak, Z., 1967. Rectangular confidence regions for the means of multivariate normal distributions. J. Am. Stat. Soc. 62, 626-633.

Southcombe, E.S.E., Miller, P.C.H., Ganzelmeier, H., Van de Zande, J.C., Miralles, A., Hewitt, A.J., 1997. The international (BCPC) Spray classification system including a drift potential factor. In: Proceedings of the Brighton Crop Protection Conference - Weeds. Brighton, UK. 5A-1, pp. 371-380.

Spillman, J.J., 1984. Spray impactions, retention and adhesions: an introduction to basic characteristics. Pest. Sci. 15, 97-106.

Uk, S., Courshee, R.J., 1982. Distribution and likely effectiveness of spray deposits within a cotton canopy from fine ultralow-volume spray applied by aircraft. Pest. Sci. 13, 529-536.

van de Zande, J.C., Porskamp, H.A.J., Holterman, H.J., 2002. Influence of reference nozzle choice on spray drift classification. Aspects of Appl. Bio. 66. Int. Adv. Pest. Appl. Wellesb. 2002, 49-56.

Wolf, R.E., Daggupati, N.P., 2009. Nozzle type effect on soybean canopy penetration. Appl. Eng. Agric. 25, 23-30.

Wolf, T.M., Harrison, S.K., Hall, F.R., Cooper, J., 2000. Optimizing postemergence herbicide deposition and efficacy through application variables in no-till systems. Weed Sci. 48, 761-768.

Zhu, H., Dorner, J.W., Rowland, D.L., Derksen, R.C., Ozkan, H.E., 2004. Spray penetration into peanut canopies with hydraulic nozzle tips. Biosyst. Eng. 87, $275-283$.

\section{References}

